\title{
Mechanical circulatory support in acute myocardial infarction complicated by cardiogenic shock
}

\author{
Ayman Al-atta ${ }^{1}$, Mohammad Zaidan $^{2}$, Ahmed Abdalwahab ${ }^{1,3}$, \\ Amjad Ghazal Asswad ${ }^{1}$, Mohaned Egred ${ }^{1}$, Azfar Zaman ${ }^{1,4}$, Mohammad Alkhali1 ${ }^{1,4, *}$ \\ ${ }^{1}$ Department of Cardiology, Freeman Hospital, NE7 7DN Newcastle upon Tyne, UK \\ ${ }^{2}$ Cardiology Department,Henry Ford Hospital, Detroit, MI 48202, USA \\ ${ }^{3}$ Cardiovascular Medicine Department, Faculty of Medicine, Tanta University, 31527 Gharbia Governorate, Egypt \\ ${ }^{4}$ Translational and Clinical Research Institute, Newcastle University, NE1 7RU Newcastle, UK \\ *Correspondence: mak-83@hotmail.com (Mohammad Alkhalil) \\ Academic Editors: John Elefteriades and Bulat Ziganshin \\ Submitted: 30 August 2021 Revised: 27 October 2021 Accepted: 27 October 2021 Published: 21 February 2022
}

\begin{abstract}
Patients with acute myocardial infarction (MI) complicated by cardiogenic shock (CS) have poor prognosis. Over the last two decades, there has been some improvement in mortality rates associated with CS. Initial measures to stabilise patients should follow a shock protocol, including therapies such as volume expansion, inotropes/vasopressors, and early coronary revascularisation. The use of mechanical circulatory support (MCS) devices demonstrated better haemodynamic and metabolic profiles for patients with CS. However, these benefits have not been consistently translated into significant reductions in cardiovascular adverse events. This review aims to discuss emerging concepts related to CS including an update on its classification and pathophysiology. The focus is on recent evidence regarding the use of MCS and the timing of initiating in patients with CS.
\end{abstract}

Keywords: Cardiogenic shock; IABP; Impella; ECMO

\section{Introduction}

Cardiogenic shock (CS) is a direct consequence of low cardiac output state leading to circulatory failure and hypoperfusion. It can result from impairment of either left or right ventricle function and may occur as an acute ischaemic or non-ischaemic event or due to progression in longstanding disease affecting the myocardium [1]. Acute myocardial infarction (MI) remains the predominant aetiology of CS, accounting for $60-80 \%$ of all cases $[1,2]$. Moreover, patients presenting with ST-segment elevation MI (STEMI) complicated by CS have a mortality rate of $40-60 \%$ [3]. Importantly, the incidence of CS is $5-10 \%$ of STEMI cases [4].

Over the last two decades, there has been some improvement in the in-hospital mortality rate related to CS. Such improvement is likely to be multifactorial. Early recognition of $\mathrm{CS}$, better triage, use of invasive haemodynamic monitoring and development of mechanical circulatory support (MCS) may have contributed to the decline in mortality [5]. Better understanding of the pathophysiology and developing standardised classification/terminology of CS have led to a better decision making regarding intervention. This review article discusses the pathophysiology and contemporary management of CS with focus on contemporary MCS devices.

\section{Definition and classification of CS}

$\mathrm{CS}$ is defined as a persistent systolic blood pressure (SBP) of less than $90 \mathrm{mmHg}$ for at least $30 \mathrm{~min}$ in the presence of primary cardiac condition with evidence of end organ dysfunction, despite adequate filling pressure [6]. The need for inotropes or vasopressor to maintain SBP $\geq 90$ is included in the majority of guidelines/trials' definitions, but less universally accepted as a criterion of CS definition. The use of MCS support was recently included in the Cardiogenic Shock Working Group and the Society of Coronary Angiography and Intervention (SCAI) definitions [7]. One of the earliest definitions of CS was proposed by Killip and Kimball as part of their classification of acute MI severity [8]. Accordingly, CS was defined as hypotension (systolic pressure of $90 \mathrm{mmHg}$ or less) and evidence of peripheral vasoconstriction such as diaphoresis, cyanosis, and oliguria [8]. The mortality rate in this group was almost three-fold higher than patients without cardiogenic shock [8]. However, variations in the definition of $\mathrm{CS}$ are evident in contemporary clinical trials adding more challenges to the interpretation and application of their results to current practice $[6,9]$. These variations are mainly related to the used criteria of defining end organ damage, which include low urine output, mottled skin, cold extremities, metabolic acidosis or raised lactate (Table 1, Ref. [10-15]). Importantly, these variations highlight the need to view CS as a continuum which progresses over time from pre-shock state to refractory CS [9]. 
To overcome these limitations, the Society of Coronary Angiography and Intervention (SCAI) has developed a system for classifying CS (Table 2) [7]. This classification was found to accurately predict mortality when applied to patients presenting with acute $\mathrm{MI}$ on admission and after 24 hours [16]. Survival to hospital discharge was the lowest $(58 \%)$ in patients in stage E compared to $76 \%$ in earlier stages C \& D [16]. Other risk scores such as Card-Shock and IABP-SHOCK II are also available for risk stratification and mortality prediction in CS [2,6]. These scores and classification systems can help triage and assess suitability of patients for MCS devices.

\section{Pathophysiology}

In acute MI, CS primarily results from reduced myocardial contractility leading to diminished cardiac output, hypotension and systemic vasoconstriction and worsening of cardiac ischaemia. The hallmark of CS is peripheral vasoconstriction and vital end-organ damage as a result of ineffective cardiac output and insufficiency of circulatory compensation. Although peripheral vasoconstriction is initially considered to be beneficial and leads to better coronary and peripheral perfusion, it can eventually lead to increased cardiac afterload jeopardizing an already burdened myocardium $[17,18]$. Compensatory mechanisms can be maladaptive and their effects can be deleterious with progressive tissue injury leading to a vicious cycle of further cardiac injury. Therapeutic interventions should attempt to interrupt this cycle by restoring cardiovascular haemodynamic stability [18].

Whist most cases of cardiogenic shock are caused by impaired LV function secondary to acute MI, mechanical and arrhythmic complications are also potential causes of CS. Other aetiologies of CS include acute and chronic heart failure, severe valvular regurgitation, non-ischaemic cardiomyopathies, acute myocarditis, and pericardial disease. Obstructive shock secondary to valvular disease or pulmonary embolism is another aetiology of CS. Right ventricle (RV) failure is a well-recognized cause of mortality in patients with CS [19]. Mechanistically, RV failure may occur because of contractile dysfunction secondary to ischaemia in acute MI setting or inflammation in cases of acute myocarditis [20]. Right-sided valvular insufficiency or increased venous return are recognized as mechanisms of volume overload in RV failure [20]. Left-sided heart failure or pulmonary hypertension can also lead to pressure overload and RV failure [20]. Recognizing the mechanism of CS would guide the use of MCS, including those that specifically target RV failure.

Pulmonary artery catheter (PAC) helps better understanding of the pathophysiology of CS. Its use is essential in classifying the stages of shock and provides information regarding the type of shock. Multiple information obtained from PAC can help categorizing shock including filling pressures, cardiac output, cardiac index, systemic vascular resistance and pulmonary vascular resistance, and cardiac power output (CPO). CPO is calculated using this formula: mean arterial pressure $\times$ cardiac output $/ 451$.

$\mathrm{CPO}$ was found to be the strongest predictor of mortality in CS patients and its value of less than 0.6 Watts was found to be an independent predictor of mortality [21,22]. Pulmonary artery pulsatility index (PAPi) is a hemodynamic parameter that is derived from right atrial and pulmonary artery pulse pressures, and calculated using this formula:

Pulmonary artery systolic pressure - pulmonary artery diastolic pressure / right atrial pressure

Several reports have described the prognostic value of PAPi in patients with advanced heart failure, cardiogenic shock and in predicting right ventricular failure post left ventricular assist device implantation [23]. PAPi has been used to identify RV failure post MI [24]. RV failure could be isolated in acute $\mathrm{MI}$ from right coronary infarction but also frequently complicates LVfailure and it could be masked by the LV failure. The availability of PA catheter data before device selection and after device implantation would guide early initiation of RV MCS [19].

A recent retrospective study showed improved inhospital mortality in patient with $\mathrm{CS}$ who received PAC to guide management [25]. Moreover, the National Cardiogenic Shock Initiative (NCSI) demonstrated that adherence to a protocol-based approach emphasising "best practices" which included the utilisation of PA catheter (92\% of patients had PA catheter monitoring) was associated with improved outcomes [22].

\section{Revascularisation in CS}

Since acute MI is the main aetiology of CS, revascularisation of the culprit lesion forms the cornerstone of treatment. In fact, Hochman et al. [26] highlighted that early revascularisation, within 6 hours, was associated with $28 \%$ relative risk reduction of death at one year (HR (Hazard ratio) $0.72 ; 95 \% \mathrm{CI}$ (confidence interval) 0.54 to 0.95 ). Additionally, the absolute risk reduction was reported as $13.2 \%$ which translated into number needed to treat of 8 patients with CS to prevent one death following early revascularization [26].

Whilst revascularising the culprit lesion is essential in the management of CS, intervening on non-culprit, but potentially haemodynamically significant lesions in patients with CS remains debatable. The CULPRIT SHOCK trial randomised 706 acute MI patients with multi-vessel disease complicated by CS into either percutaneous coronary intervention (PCI) of the culprit-lesion only with the option of staged revascularisation of the non-culprit lesions at later stage, or immediate multi-vessel PCI [10]. Notably, 24\% of patients in the immediate multi-vessel PCI group had chronic total occlusion (CTO) and revascularisation may increase the risk of complications and contrast use with likely low success rate. In fact, PCI CTO in the CULPRIT 
Table 1. Definition of cardiogenic shock in main trials and guidelines.

\begin{tabular}{|c|c|c|c|c|c|}
\hline Shock Trial [12] & Triumph [14] & IABP-SHOCK II [13] & EHS PCI [15] & ESC-HF Guidelines [11] & Culprit Shock [10] \\
\hline $\begin{array}{l}\mathrm{SBP}<90 \mathrm{mmHg} \text { for } \geq 30 \mathrm{~min} \text { or } \\
\text { vasopressor support to maintain } \\
\mathrm{SBP}>90 \mathrm{mmHg}\end{array}$ & $\begin{array}{l}\text { Refractory cardiogenic shock } \\
>1 \mathrm{~h} \text { after PCI with SBP } \\
<100 \mathrm{mmHg} \text { despite vasopres- } \\
\text { sors (dopamine } \geq 7 \mu \mathrm{g} / \mathrm{kg} / \mathrm{min} \\
\text { or norepinephrine or epinephrine } \\
\geq 0.15 \mu \mathrm{g} / \mathrm{kg} / \mathrm{min} \text { ) associated } \\
\text { with end organ hypoperfusion }\end{array}$ & $\begin{array}{l}\text { MAP }<70 \mathrm{mmHg} \text { or SBP } \\
<100 \mathrm{mmHg} \text { despite adequate } \\
\text { fluid resuscitation (at least } 1 \mathrm{~L} \\
\text { of crystalloids or } 500 \mathrm{~mL} \text { of } \\
\text { colloids) }\end{array}$ & $\begin{array}{l}\mathrm{SBP}<90 \mathrm{mmHg} \text { for } 30 \mathrm{~min} \text { or use } \\
\text { of inotropes to maintain } \mathrm{SBP} \geq 90 \\
\mathrm{mmHg} \text { with evidenceof end organ } \\
\text { damage and increased filling } \\
\text { pressure }\end{array}$ & $\begin{array}{l}\text { SBP }<90 \mathrm{mmHg} \text { with appropria } \\
\text { fluid resuscitation with clinical and } \\
\text { laboratory evidence of end-organ } \\
\text { damage (cold extremities, oliguria, } \\
\text { altered mental status, narrow pulse } \\
\text { pressure, metabolic acidosis, elevated } \\
\text { serum lactate, elevated serum creati- }\end{array}$ & $\begin{array}{l}\mathrm{SBP}<90 \mathrm{mmHg} \text { for }>30 \mathrm{~min} \text { or } \\
\text { use of catecholamines to maintain } \\
\mathrm{SBP}>90 \mathrm{mmHg}\end{array}$ \\
\hline $\begin{array}{l}\text { Evidence of end-organ damage } \\
\text { (urine output }<30 \mathrm{~mL} / \mathrm{h} \text { or cool } \\
\text { extremities) } \\
\text { Hemodynamic criteria: cardiac } \\
\text { index }<2.2 \text { and pulmonary capil- } \\
\text { lary wedge pressure }>15 \mathrm{mmHg}\end{array}$ & $\begin{array}{l}\text { Clinical or haemodynamic criteria } \\
\text { for elevated left ventricular filling } \\
\text { pressure with left ventricle ejection- } \\
\text { fraction }<40 \%\end{array}$ & $\begin{array}{l}\text { Evidence of end-organ damage } \\
\text { (Altered mental status, mottled } \\
\text { skin, urine output }<0.5 \mathrm{~mL} / \mathrm{kg} \\
\text { for } 1 \mathrm{~h} \text {, or serum lactate }>2 \\
\mathrm{mmol} / \mathrm{L} \text { ) }\end{array}$ & & nine & $\begin{array}{l}\text { Pulmonary congestion with impair- } \\
\text { ed organ perfusion (Altered mental } \\
\text { status, cold/clammy skin and extre- } \\
\text { mities, urine output }<30 \mathrm{~mL} / \mathrm{h} \text {, } \\
\text { lactate }>2.0 \mathrm{mmol} / \mathrm{L}\end{array}$ \\
\hline
\end{tabular}


Table 2. Society of Coronary Angiography and Intervention (SCAI) classification of shock [7].

\begin{tabular}{|c|c|c|c|c|c|c|}
\hline Stage & Cardiovascular & Lung & Neurology & Renal \& liver function & Lactate \& BNP & Haemodynamic \\
\hline A (At Risk) & $\begin{array}{l}\text { Warm and well perfused } \\
\text { Strong distal pulses } \\
\text { Normotensive } \\
\text { Normal JVP }\end{array}$ & Clear & Intact & Normal & Normal & $\begin{array}{l}\mathrm{CI} \geq 2.5 \\
\mathrm{CVP}<10 \\
\mathrm{PA} \text { sat } \geq 65 \%\end{array}$ \\
\hline B (Beginning of CS) & $\begin{array}{l}\text { Warm and well perfused } \\
\text { Strong distal pulses } \\
\text { Tachycardia }(\geq 100) \text { and Hypoten- } \\
\text { sion (SBP }<90 \text {, or MAP }<60 \text {, or } \\
>30 \text { mmHg drop from baseline) } \\
\text { without hypoperfusion } \\
\text { Elevated JVP }\end{array}$ & Rales in lung fields & Intact & Minimal impairment & $\begin{array}{l}\text { Normal } \\
\text { Elevated BNP }\end{array}$ & $\begin{array}{l}\mathrm{CI} \geq 2.2 \\
\text { PA sat } \geq 65 \%\end{array}$ \\
\hline C (Classic CS) & $\begin{array}{l}\text { Cold \& clammy } \\
\text { Hypotension (SBP }<90 \text {, or MAP } \\
<60 \text {, or }>30 \mathrm{mmHg} \text { drop from base- } \\
\text { line) and drugs/device used to main- } \\
\text { tain BP beyond volume resuscitation } \\
\text { to restore perfusion. }\end{array}$ & $\begin{array}{l}\text { Extensive rales } \\
\text { Killip class } 3 \text { or } 4 \\
\text { BiPap or mechanical ventilation }\end{array}$ & Acute alteration in mental status & $\begin{array}{l}\text { Creatinine doubling or }>50 \% \text { drop in GFR } \\
\text { Urine output }<30 \mathrm{~mL} / \mathrm{h} \\
\text { Increased LFTs }\end{array}$ & $\begin{array}{l}\text { Lactate } \geq 2 \\
\text { Elevated BNP }\end{array}$ & $\begin{array}{l}\mathrm{CI}<2.2 \\
\mathrm{PCWP}>15 \\
\mathrm{RAP} / \mathrm{PCWP} \geq 0.8 \\
\mathrm{PAPI}<1.85 \\
\text { cardiac power output } \leq 0.6\end{array}$ \\
\hline D (Deteriorating/Doom) & $\begin{array}{l}\text { Cold \& clammy } \\
\text { Hypotension (SBP }<90 \text {, or MAP }<60 \text {, } \\
\text { or }>30 \mathrm{mmHg} \text { drop from baseline) and } \\
\text { failing to re-spond to initial interventions } \\
\text { with drugs/device requiring multiple pre- } \\
\text { ssors or addition of mechanical circu- } \\
\text { latory support devices to maintain } \\
\text { perfusion }\end{array}$ & $\begin{array}{l}\text { Extensive rales } \\
\text { Killip class } 3 \text { or } 4 \\
\text { BiPap or mechanical ventilation }\end{array}$ & Deteriorating from stage $\mathrm{C}$ & Deteriorating from stage $\mathrm{C}$ & $\begin{array}{l}\text { Lactate } \geq 2 \\
\text { Elevated BNP }\end{array}$ & Deteriorating from stage $\mathrm{C}$ \\
\hline E (Extremis) & $\begin{array}{l}\text { Near Pulselessness } \\
\text { No SBP without resuscitation } \\
\text { PEA or refractory VT/VF with on- } \\
\text { going CPR }\end{array}$ & Mechanical ventilation & Unconscious & Deteriorating from stage $\mathrm{D}$ & $\begin{array}{l}\mathrm{PH} \leq 7.2 \\
\text { Lactate } \geq 5\end{array}$ & Cardiac collapse \\
\hline
\end{tabular}


SHOCK trial was successful in only one third of patients. This becomes more important since the primary endpoint was the composite of death and severe renal failure leading to renal replacement therapy which occurred in $46 \%$ in the culprit lesion-only group compared to $55.4 \%$ in the multivessel PCI (relative risk $0.83,95 \%$ CI 0.71 to $0.96, p=0.01$ ) [10]. The relative risk of death was 0.84 (95\% CI 0.72 to $0.98, p=0.03)$ favouring the former group. Similarly, the relative risk of renal placement therapy was 0.71 (95\% CI 0.49 to $1.03, p=0.07$ ).

Of note, only $28 \%$ of patients in the CULPRIT SHOCK received MCS. Recent data from the NCSI regarding patients with multivessel disease presenting with acute $\mathrm{MI}$ and receiving early MCS, showed that intervening on the non-culprit lesions was safe and associated with comparable rate of death and acute kidney injury to patients who received PCI of the culprit-lesion only [27]. Interestingly, this data suggested that in patients presenting with non-ST-segment elevation MI (NSTEMI) with multi-vessel disease and CS, revascularisation of the non-culprit lesions was associated with a lower risk of in-hospital mortality but a higher risk of bleeding and need for renal replacement therapy [28]. Nevertheless, mortality rate in those who survived to hospital discharge was comparable between the two groups over 7 years follow up [28]. Current guidelines recommend immediate revascularisation of the culprit vessel and complete revascularisation should be considered during the index admission in patients with CS [3].

\section{Pharmacotherapy in the management of CS}

Stabilising patients with CS starts by identifying the mechanism of the shock. Fluid challenge, unless there is overt signs of fluid overload, vasopressor and inotropes are considered part of the initial measures. Vasopressors should be used in minimum doses and there is paucity of data to suggest an optimal blood pressure target with these agents $[6,29]$. Noradrenaline is considered the vasoconstrictor of choice in CS [11]. Noradrenaline had lower mortality rate when compared with dopamine [30], and a better metabolic and safer profile compared to epinephrine [31,32].

Inotropic support to improve cardiac contractility is also used in patients with CS. Dobutamine is the most commonly used agent [11]. Caution should be exercised when inotropic agents are used particularly at high doses as these agents can worsen ischaemia in an already compromised myocardium. Newer agents such as levosimendan have received some interest given their mechanism of action in improving cardiac contractility without increasing oxygen requirement. Nonetheless, levosimendan was not associated with mortality benefits or organ protection in patients undergoing cardiac surgery [33]. More recently, milrinone was compared to dobutamine in 192 patients with CS. The primary endpoint of in-hospital death, resuscitated cardiac arrest, receipt of a cardiac transplant or mechanical circu- latory support, nonfatal myocardial infarction, transient ischemic attack or stroke, or initiation of renal replacement therapy was comparable between the two agents (relative risk $0.90,95 \%$ CI 0.69 to $1.19, p=0.47$ ) [34]. Overall, existing evidence does not support the use of a single inotropic agent over another, but a signal of mortality reduction was evident when inotropes were added to vasopressors [35].

\section{Mechanical circulatory support in CS}

Advances in technology have allowed rapid development of devices that mechanically support the failing heart. These devices range from intra-aortic balloon pump (IABP), transvalvular axial flow pumps including Impella 2.5, LP, CP, 5.0 and 5.5, TandemHeart and extracorporeal membrane oxygenation (ECMO). These devices have different mechanisms of supporting patients with CS and different indications that need to be tailored to patients' presentation and clinical status. For those with predominantly right ventricle failure, for example, RP Impella and TandemHeart can be used whilst bilateral Impella and VA ECMO would benefit patients with biventricular failure. Moreover, the ability of MCS devices varies in altering myocardial oxygen demand or augmenting coronary blood flow and is based on the design of each device (Figs. 1, 2) [36]. For example, ECMO decreases native cardiac output, increases end-organ perfusion, improves tissue oxygen delivery, but does not address the underlying pathophysiology in CS. Evaluating patients for MCS should take into consideration the haemodynamic deficit of the patient and the therapeutic goal of whether MCS is a bridge to recovery, long-term mechanical support (transplant or left ventricular assist device, LVAD), or to a decision, particularly in patients with an undetermined prognosis. Other factors such as complication risk, operator expertise in device implantation and management alongside institutional experience and the available level of care are all key aspects in the decision of MCS in CS.

Additionally, the timing to use MCS devices to support the heart is also an important factor in preventing progression of reversible haemodynamic to an irreversible phase and refractory shock. In a relatively small registry of 41 consecutive patients with CS, early use of MCS alongside invasive haemodynamic monitoring was associated with improved survival when compared with historic records from the same participating centres [37]. More recently, the Door-To-Unload in STEMI Pilot Trial compared the use of Impella CP with 30 min delay to unload the LV to the use of Impella CP followed by immediate revascularisation in 50 patients with anterior STEMI [38]. Clinical adverse events were comparable and, likewise, infarct size, quantified at 30 days, was similar between the two groups [38]. Importantly, this study included anterior STEMI patients without cardiogenic shock but highlighted the safety of using MCS prior to revascularisation as a novel way to protect the myocardium from ischaemia-reperfusion injury. 


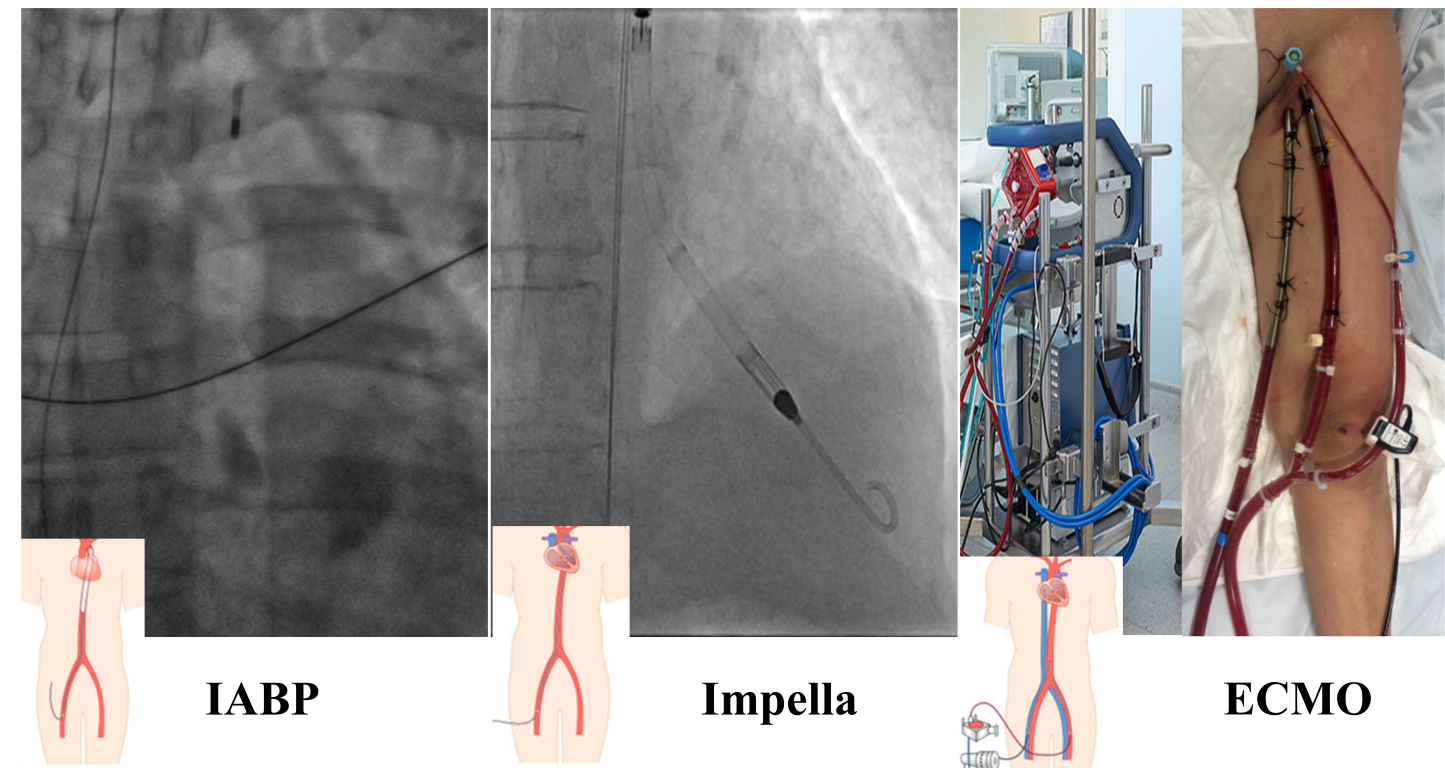

Fig. 1. Mechanical Circulatory Support devices. Schematic illustration of various mechanical circulatory support devices highlighting vascular access and relationship to the heart. IABP, intra-aortic balloon pump; ECMO, extracorporeal membrane oxygenation.

\begin{tabular}{|l|l|l|l|l|l|l|l|}
\hline MCS & Afterload & LVEDP & MAP & CO & $\begin{array}{l}\text { Left } \\
\text { Ventricular } \\
\text { Unloading }\end{array}$ & $\begin{array}{l}\text { Myocardial } \\
\text { Oxygen } \\
\text { Demand }\end{array}$ & $\begin{array}{l}\text { Maximal Flow } \\
\text { (L/min) }\end{array}$ \\
\hline IABP & $\downarrow$ & $\downarrow$ & $\uparrow$ & $\uparrow$ & $\uparrow$ & $\downarrow$ & 0.5 \\
\hline Impella CP & Variable & $\downarrow$ & $\uparrow$ & $\uparrow$ & $\uparrow$ & $\downarrow$ & 4.0 \\
\hline Tandem Heart & $\Leftrightarrow$ & $\downarrow$ & $\uparrow$ & $\uparrow$ & $\uparrow$ & $\downarrow$ & \\
\hline VA-ECMO & $\uparrow$ & $\uparrow$ to $\Leftrightarrow$ & $\uparrow$ & $\uparrow$ & $\downarrow$ & $\Leftrightarrow$ & 7.0 \\
\hline
\end{tabular}

Fig. 2. Changes in hemodynamic, cardiac output and oxygen consumption in response to various mechanical circulatory support devices. Changes in after-load, left ventricle end diastolic pressure (LVEDP), mean arterial pressure (MAP), alongside maximal flow are illustrated for intra-aortic balloon pump (IABP), Impella, TandemHeart, and VA-ECMO.

Early initiation of MCS devices before the onset of cardiogenic shock is currently been studied using Impella in the DanGer shock study [39], or using ECMO in the ECLSSHOCK, EURO-SHOCK, and the ECMO-CS trials [4042]. Table 3 summarized ongoing trials of patients presenting with CS.

\section{Intra-aortic balloon pump (IABP)}

IABP has been in use for approximately five decades, and is considered the most commonly used MCS in CS [6]. It mainly works by augmenting diastolic pressure to improve coronary perfusion pressure leading to an improvement in cardiac output of up to 0.5 to $1 \mathrm{~L} / \mathrm{min}$ depending on the balloon size in relation to aorta [4]. IABP also leads to a reduction in cardiac afterload leading to improvement in myocardial oxygen consumption $[4,6]$.

Earlier data from randomised and non-randomised trials suggested mortality benefit from IABP in STEMI patients with CS, particularly in the thrombolytic era $[43,44]$. A sub-group analysis of the landmark SHOCK trial showed an improved survival with IABP, although the survival benefit was greater with early revascularization independent of IABP use [12]. Mechanistically, De Silva studied the effects of IABP on coronary microcirculation in a small study of thirteen patients with ischaemic cardiomyopathy undergoing PCI [45]. The authors highlighted that both coro- 
nary distal pressure as well as microcirculatory resistance were increased in the presence of IABP without significant changes to coronary flow which was quantified using doppler-flow wire [45]. Following adenosine administration, coronary flow was significantly increased and closely related to the diastolic forward pressure generated by IABP [45]. The authors proposed that the autoregulatory feature of coronary circulation ameliorated the effect of IABP and concluded that the benefits of IABP would be better realised in patients with dysfunctional microcirculation reserve.

Nevertheless, both IABP-SHOCK and IABP-SHOCK II trials failed to show any incremental benefits when using IABP in CS when compared to standard medical therapy $[13,46]$. IABP did not improve the haemodynamic profile or the need for inotropic/vasopressors, nor did it result in mortality reduction over 6 years follow up [13,46,47]. A large meta-analysis of 12 randomised trials, including 2123 patients showed that IABP did not improve survival in patients presenting with acute MI, regardless of the presence of CS [48]. Subsequently, the 2017 European Society of Cardiology (ESC) guidelines discouraged the routine use of IABP (Class IIIB) in patients with acute MI complicated with CS [3].

IABP was also proposed as a pre-emptive strategy to prevent CS in patients undergoing high risk PCI. The Balloon Pump Assisted Coronary Intervention Study (BCIS-1) was one of the earliest trials that investigated the role of IABP in 301 patients with severely impaired LV systolic function and extensive coronary artery disease undergoing PCI [49]. There was no difference in the in-hospital adverse events between patients who received elective IABP and those who did not (odds ratio, $0.94,95 \%$ CI 0.51 to $1.76, p$ $=0.85$ ) [49]. Similarly, all-cause mortality at 6 months was not different between the two groups [49]. Interestingly, 5 years follow up data suggested a significant reduction in all-cause mortality [50]. Gu et al. [51] reported that the use of IABP in high risk PCI was associated with a reduction in inflammatory markers, troponin level, in-hospital and 30day mortality. However, the decrease in mortality was not evident at 6 months [51]. This inconsistency in existing literature does not support the routine use of IABP in patients undergoing high-risk PCI. Overall, the role of IABP in contemporary practice is restricted. Nevertheless, it should be considered (class IIA) in patients with CS associated with mechanical complication of acute MI [3]. Moreover, it can potentially be used in combination with other MCS devices pending new evidence from ongoing trials.

IABP is a generally considered a safe device, nonetheless, its use was associated with increased risk of stroke and bleeding complications $[52,53]$. The relative contraindications of IABP use include severe peripheral vascular disease, the presence of significant coagulopathy or sepsis. It is absolutely contraindicated in patients with severe aortic regurgitation or aortic dissection. Complications occur with a frequency of about $5 \%$ during or following IABP insertion [54]. These complications are mainly vascular related to trauma or dissection and can manifest itself as haematoma, haemothorax, compartment syndrome, limb or organ ischaemia either acutely or insidiously. The use of smaller size or sheathless catheters may reduce the risk of complications [55].

\section{Impella}

The Impella device is a catheter-based microaxial flow pump that delivers blood from the left ventricle into the ascending aorta or in case of RP device, from the inferior vena cava into the pulmonary artery. The output using Impella could reach up to $5.5 \mathrm{~L} / \mathrm{min}$ depending on the used device. The Impella family has a spectrum of devices with different flow rates. Impella $2.5(2.5 \mathrm{~L} / \mathrm{min})$ and Impella CP (up to $4.3 \mathrm{~L} / \mathrm{min}$ ) are both inserted retrogradely via the femoral artery. The Impella 2.5 requires $13 \mathrm{~F}$ access site compared to $14 \mathrm{~F}$ when using Impella $\mathrm{CP}$. The comparable access size between the two devices has led to adoption of Impella CP for CS. Impella 5.0 requires a surgical cut-down due its size. This can be inserted via the axillary artery via a cut-down procedure. This would facilitate patient mobilisation while on Impella support.

Experimental studies suggested that Impella can offload the left ventricle and improve coronary perfusion [56]. Early human studies have highlighted the role of Impella in increasing cardiac output, reducing pulmonary wedge pressure, and improving organ perfusion [57]. The ability to offload the left ventricle is a useful feature to allow bridging to recovery during the initial phase of ventricular stunning in patients with acute MI complicated by CS.

There is a lack of adequately powered randomised trials to assess the role of Impella in CS. The EURO-SHOCK study was a retrospective multi-centre study of 120 patients with acute MI complicated by CS [58]. The use of Impella 2.5 was associated with a significant reduction in lactate level after 48 hours suggesting improved organ perfusion. However, mortality rate remains high with only 1 in 4 patients survived after 10-month follow up [58]. In the Efficacy Study of LV Assist Device to Treat Patients With Cardiogenic Shock (ISAR-SHOCK) study, Impella LP 2.5 was demonstrated to be safe and feasible in patients with acute MI complicated by CS [59]. However, Impellla did not improve 30-day mortality compared to IABP in this randomised study of 25 patients, despite the significant increase in cardiac index with Impella after 30 min of support [59]. Moreover, the IMPella versus IABP Reduces mortality in STEMI patients treated with primary PCI in Severe cardiogenic SHOCK (IMPRESS) study showed that the routine use of Impella did not improve 30-day or 6month mortality when compared to IABP [60]. In a relatively small study of 25 patients, Impella 5.0 and upgrading from Impella 2.5 to 5.0 was associated with improved clinical outcomes when compared with Impella 2.5 [61]. However, this study was not randomised, and the reported mor- 


\begin{tabular}{|c|c|c|c|c|}
\hline Trial/Study & Design & Population & Intervention & Outcome \\
\hline $\begin{array}{l}\text { EuroShock } \\
(\mathrm{n}=428) \\
\text { NCT03813134 }\end{array}$ & RCT, multicentre, open label & ACS patients with CS & $\begin{array}{l}\text { VA-ECMO support initiated early after PCI + Pharmac- } \\
\text { otherapy versus pharmacotherapy alone }\end{array}$ & 30-day all-cause mortality \\
\hline $\begin{array}{l}\text { REVERSE } \\
(\mathrm{n}=96) \\
\text { NCT03431467 }\end{array}$ & RCT, single blinded (assessor) & CS from various aetiologies & $\begin{array}{l}\text { VA-ECMO with early initiation of CP LV venting versus } \\
\text { VA-ECMO alone per standard protocol }\end{array}$ & Recovery from cardiogenic shock at 30 days \\
\hline $\begin{array}{l}\text { ECMO-CS } \\
(\mathrm{n}=120) \\
\text { NCT02301819 }\end{array}$ & RCT, single blinded & $\mathrm{CS}-$ various aetiologies & $\begin{array}{l}\text { VA-ECMO + Standard management including PCI or } \\
\text { surgical revascularization versus Standard management } \\
\text { including revascularization }\end{array}$ & $\begin{array}{l}\text { 30-day Composite of death from any cause, } \\
\text { resuscitated circulatory arrest, and } \\
\text { implantation of another mechanical }\end{array}$ \\
\hline $\begin{array}{l}\text { DanGer Shock } \\
(\mathrm{n}=360) \\
\text { NCT01633502 }\end{array}$ & $\begin{array}{l}\text { RCT, open label, multicentre, } \\
\text { prospective }\end{array}$ & AMICS & $\begin{array}{l}\text { Impella CP } \\
\text { Placed before angioplasty in those with AMICS versus } \\
\text { standard management }\end{array}$ & $\begin{array}{l}\text { circulatory support device } \\
\text { All-cause mortality at } 180 \text { days }\end{array}$ \\
\hline $\begin{array}{l}\text { SMART-RESCUE II } \\
(\mathrm{n}=1000) \\
\text { NCT04143893 }\end{array}$ & Observational & CS of various aetiologies & $\begin{array}{l}\text { Comparison of those with CS who underwent MCS }+ \\
\text { medical therapy including a vasopressor versus those who } \\
\text { were treated with medical therapy including a vasopressor }\end{array}$ & In-hospital mortality up to 12 weeks \\
\hline $\begin{array}{l}\text { CSWG } \\
(\mathrm{n}=5000) \\
\text { NCT04682483 }\end{array}$ & Registry & CS of various aetiologies & $\begin{array}{l}\text { Patients meeting criteria for CS as defined by the group, } \\
\text { and underwent MCS management by any of the available } \\
\text { devices }\end{array}$ & 30-day and one-year mortality \\
\hline $\begin{array}{l}\text { CARDSUP } \\
\text { NCT04117230 }\end{array}$ & Registry & CS of various aetiologies & $\begin{array}{l}\text { All patients requiring MCS support with an any Impella } \\
\text { device or VA-ECMO }\end{array}$ & 30-day mortality \\
\hline $\begin{array}{l}\text { ECLS-SHOCK } \\
(\mathrm{n}=420) \\
\text { NCT03637205 }\end{array}$ & RCT, prospective, open label & AMICS & $\begin{array}{l}\text { AMICS treated with ECLS (preferably before PCI) under- } \\
\text { going revascularization preferably by PCI versus revascul- } \\
\text { arization and standard medical therapy }\end{array}$ & 30-day mortality \\
\hline $\begin{array}{l}\text { Altshock-2 } \\
(\mathrm{n}=200) \\
\text { NCT04295252 }\end{array}$ & RCT, Multi-centre, Open label & $\begin{array}{l}\text { Decompensated heart failure with } \\
\text { CS }\end{array}$ & $\begin{array}{l}\text { Early initiation of IABP (within } 6 \text { hrs) in those with CS } \\
\text { versus standard medical therapy }\end{array}$ & $\begin{array}{l}\text { Successful bridge to transplantation or LVAD (at } \\
60 \text { days) } \\
\text { Survival at } 60 \text { days }\end{array}$ \\
\hline $\begin{array}{l}\text { Outcomes of patients } \\
\text { treated with IABP } \\
(\mathrm{n}=1000)\end{array}$ & Observational & $\begin{array}{l}\mathrm{CS} \text { due to ACS, Heart failure } \\
\text { or post-cardiac surgery }\end{array}$ & Patients treated with IABP & 30-day all-cause mortality \\
\hline
\end{tabular}

ACS, Acute coronary syndrome; AMICS, Acute Myocardial Infarction with Cardiogenic Shock; CAD, Coronary Artery Disease; CS, Cardiogenic Shock; CSWG, Cardiogenic Shock Working Group; CV, Cardiovascular; ECLS, Extracorporeal Life Support; IABP, Intra-aortic Balloon Pump; LVAD, Left Ventricular Assist Device; MCS, Mechanical Circulatory Support; VA-ECMO, Veno-arterial Extra-corporeal Membrane Oxygenation. 
tality was the crude rate without adjustment for other clinical variables [61]. Additionally, the use of surgically implanted Impella is more invasive and associated with more complications, although the incidence of vascular complications is generally increased with the use of MCS devices [62]. A study-level meta-analysis including four studies highlighted the neutral effect of Impella in improving 30day mortality rate in patients with acute MI complicated by CS [63]. Notably, vascular complications, including lifethreatening bleeding, were consistently associated with the use of Impella compared to standard treatment or IABP use $[60,64]$. This highlights the need to have a better patient selection for MCS for both safety and efficacy. A significant proportion of included patients could be classified as stage E according to the SCAI Shock classification. This group may have reached an irreversible stage of CS and the use of MCS may be a too late to alter outcome. Additionally, early timing for initiating haemodynamic support was suggested by the US registry of 154 consecutive patients who underwent Impella 2.5 and PCI from 38 US hospitals [65]. Patients who received haemodynamic support pre-PCI had more lesions treated, which was translated into significantly better in-hospital survival compared to patients who received haemodynamic support post PCI (65\% vs. 41\%, $p=0.003$ ) [65]. Subsequently, the Detroit CS Initiative highlighted the prognostic role of early initiation of MCS before PCI or receiving inotropes/vasopressors in acute MI patients complicated by CS $[37,66]$. A recent meta-analysis suggested a survival benefit when using Impella pre- compared to post PCI [67]. Whilst current data support the role of Impella in improving haemodynamic and organ perfusion, optimal patient selection alongside timing of initiating haemodynamic support are plausible factors contributing to the lack of survival benefits when using Impella. The Door-To-Unload (DTU)-STEMI pilot study highlighted the safety and feasibility of early initiation of haemodynamic support in anterior STEMI without cardiogenic shock [38]. High risk PCI patients are another group that may benefit from early haemodynamic support. A few studies have investigated the role of Impella, mainly 2.5, as pre-emptive strategy to prevent $\mathrm{CS}$ in patients undergoing high risk PCI [68-70]. Nonetheless, the PROTECT II study did not demonstrate mortality benefits with Impella compared to IABP in 452 patients undergoing high risk PCI [71]. The 30-day adverse clinical events were comparable between the two groups ( $35 \%$ vs. $40 \%, p=0.22)$ [71]. The PROTECT IV trial is currently recruiting high risk PCI with low EF and assessing the role of Impella in comparison to IABP.

Impella devices are relatively contraindicated in patients with severe aortic stenosis, however, some centres reported successful use of the device in this setting while undergoing PCI or transcatheter aortic valve replacement $[72,73]$. It is absolutely contraindicated in those who cannot receive anticoagulation or those with severe peripheral vascular disease. Ventricular septal defect is another major contraindication as a significant right to left shunt would be created by the device [74]. As with many MCS devices, thrombosis is an important complication, which is usually avoided by administering systemic anticoagulation however at cost of high incidence of bleeding of up to $30 \%$ with Impella devices [75]. Haemolysis is another significant complication and its incidence is variably reported between $8 \%$ to $63 \%[69,76]$. Such variation may reflect the local methods of management of Impella and usually is addressed by repositioning the device or managing the preload [77]. The incidence of other complications includes vascu$\operatorname{lar}(10 \%)$, bleeding requiring transfusion $(17.5 \%)$ or requiring surgical intervention (2.6\%) [74]. These complications were reported more frequently with Impella compared to IABP $[63,65]$.

\section{Peripheral Veno-arterial ECMO (VA-ECMO)}

ECMO was first introduced in the 1970s to support respiratory and cardiac function, with no conclusive evidence of survival advantage over conventional therapies. VA-ECMO involves oxygenating venous blood obtained via 15-29F cannula and pumping it into arterial circulation via a centrifugal pump providing a flow of about 4$6 \mathrm{~L} / \mathrm{min}$. VA-ECMO can be connected centrally between the right atrium and the aorta or peripherally by connecting femoral vein and femoral artery. Whilst, VA-ECMO can provide excellent biventricular support, it can increase systemic afterload, LV dilation and stasis, and pulmonary congestion requiring other tools to offload the left ventricle. Decreasing pump flow may help in reducing LV afterload, or by commencing inotropes or vasodilator to allow $\mathrm{LV}$ venting. The well-oxygenated retrograde blood from ECMO mixes with the native blood leaving the heart at a mixing point. If this point is distal to the left subclavian, then vital organs, i.e., brain and heart will receive poorlyoxygenated blood while other organs will receive welloxygenated blood (Harlequin syndrome) [4]. This phenomenon is not completely eliminated by providing ECMO retrograde flow at proximal site to the femoral artery, i.e., left subclavian or innominate arteries), but rather by reinfusing well-oxygenated blood into both the arterial and venous cannulas (venoarterial-venous ECMO configuration) [4].

Retrospective studies highlighted the feasibility of using ECMO in refractory CS [78-80]. Those studies highlighted a relatively better in-hospital survival rate of more than $30 \%$ in critically unwell patients. Unsuccessful angioplasty, pulseless electrical activity, and complications related to ECMO were among the predictors of in-hospital mortality. Bleeding complications and multi-organ failure were observed at the induction of ECMO leading to early treatment failure. In a meta-analysis of thirteen studies, Ouweneel et al. [81] reported that the use of ECMO was 
associated with $13 \%$ absolute increase in 30-day survival rate compared to patients without ECMO. Notably, in CS patients ECMO was associated with $33 \%$ relative increase in 30-day survival rate when compared with IABP. A difference that was not evident when ECMO was compared to TandemHeart or Impella [81].

Patients outcome was also shown to be time-sensitive while on ECMO [82]. There was more than 50\% increase in the odds of death in patients who had their ECMO weaned off before day 4, likely reflecting treatment failure [82]. In contrast, those who had their ECMO treatment for $>4$ but $<12$ days had $14 \%$ reduction in their in-hospital mortality rate, with no difference in death after day 12 on ECMO [82]. Age was also identified as a significant predictor of mortality in patients undergoing ECMO treatment $[83,84]$. Despite similar initial hemodynamic response, inhospital and mid-term outcomes were worse in elderly patients i.e., above age of 60 (94\% vs. $68 \%, p=0.001)$ $[83,84]$. Nonetheless, this group had an acceptable survival rate to hospital discharge and age should not be considered as an absolute contra-indication for ECMO treatment [85].

Brunner et al. [86] performed the first randomised trial comparing the use of ECMO to no mechanical support in 42 patients with acute MI complicated by CS. Almost all patients $(95 \%)$ had resuscitated cardiac arrest. Patients in the control group were older and had a higher number of diseased vessels. The primary endpoint was left ventricle ejection fraction at 30 days which was comparable between the two groups. Notably, the length of stay in intensive care unit and duration of mechanical ventilation was significantly less in the ECMO group. Moreover, the 30-day survival rate was numerically higher in the ECMO compared to the control group ( $33 \%$ vs. $19 \%, p=0.37$ ), and the difference remained similar after one-year follow up [86,87]. Ongoing randomised studies will add more insights into the role of ECMO in patients with CS.

Severe peripheral vascular disease may preclude the use of peripheral ECMO. The need for prolonged cannulation would subject patients to access site complications and bleeding, particularly when there is a continuous requirement for systemic anticoagulation. The most frequently reported complications include bleeding 33\%, sepsis 33\%, and acute renal failure requiring dialysis in $52 \%$. Venous thrombosis occurred in $10 \%$, and limb ischaemia in $10 \%$ of cases, while neurological complications were reported in up to $8 \%$ of cases $[88,89]$.

\section{TandemHeart}

This device pumps blood from the left atrium into the aorta bypassing the LV and, hence, can decrease preload, increase mean arterial pressure, and avoids problems with pulmonary congestion that are seen with ECMO. However, it can potentially increase the afterload secondary to the retrograde aortic flow. The maximum circulatory support can reach $5 \mathrm{~L} / \mathrm{min}$. TandemHeart relies on the right ventri- cle function and as long as it is satisfactory, it can provide haemodynamic support even with the occurrence of transient arrhythmias or in the presence of extreme tachycardia. Its use is limited by the need for training and expertise availability as it is more invasive compared to other MCS requiring trans-septal puncture.

There is very limited evidence for the use of this device with only 2 small randomized trials performed [90,91]. TandemHeart improved haemodynamic, metabolic and cardiac power index in a relatively small study of 41 patients when compared to standard treatment, including IABP [90]. Similarly, TandemHeat increased mean arterial blood pressure and significantly decreases pulmonary capillary wedge pressure [91]. Nonetheless, the survival rate was comparable between the two groups [90,91]. Importantly, the use of TandemHeart was associated with increased limb ischaemia and bleeding complications. Further studies are needed to clarity its role among other MCS devices.

\section{Combined mechanical support}

Combining different MCS devices has been used to obtain better haemodynamic profile and/or to ameliorate side effects or shortcomings of some devices such as ECMO. In an experimental study of 7 sheep models, the use of Impella alongside IABP provided the most favourable haemodynamic profile compared to either device alone [92]. Human data are limited on the use of Impella and IABP, however, a small randomised trial assessed the change in haemodynamic in response to adding Impella LP to acute MI patients complicated by CS and managed by IABP [93]. After 12 hours, there was no significant difference in cardiac power index between the two groups, which persisted even after 96 hours of Impella treatment. Subsequently, LV ejection fraction was comparable between the two groups with higher incidence of major bleeding in the combined group [93].

It is well-established that peripheral VA-ECMO can lead to increased LV afterload with subsequent left ventricular distension as a result of the retrograde aortic flow. The worseningafterload can cause an increase in left atrial pressure, pulmonary oedema and can result in myocardial ischaemia. The combination of VA-ECMO with either a surgical or percutaneous device might be required to decompress or vent the left ventricle. This becomes important when the underlying pulsatility of the LV is unable to adequately compete with the retrograde flow from ECMO circuit leading to LV overload and thrombosis.

Data supporting the incremental benefits of concomitant use of IABP and ECMO were conflicting and likely related to the small sample size and the observational nature of the included studies. Several meta-analyses reported that the use of IABP alongside ECMO, particularly in patients with acute MI. The combination of ECMO and IABP was associated with a significant reduction of $10-20 \%$ in all-cause mortality compared to patients with ECMO only 
[94,95]. Importantly, gastrointestinal and limb ischaemia were not different between the two groups [94,95]. A recent small study of 18 patients presenting with STEMI complicated with CS and underwent ECMO showed better neurological outcome compared to those receiving ECMO only [96]. The survival rate was also better in the former group, despite having more complex coronary anatomy.

Impella is increasingly being used as an adjunctive device to offload the LV in patients on ECMO. Moreover, the combination is maybe indicated in patients with right ventricle failure or persistent low cardiac output. In fact, it becomes a routine practice in some centres to concurrently initiate support with both devices with a signal of improved outcomes [97]. In the largest US retrospective registry, concomitant use of Impella and ECMO was associated with a significant reduction in 30-day mortality when compared with patients receiving ECMO alone (57\% vs. 78\%, $p=$ 0.02) [98]. Likewise, the use of inotropes was lower in the combination group with remarkably similar safety profile [98].

Other forms of unloading the LV are reported using percutaneous or surgical left atrial cannulation but data are limited on its efficacy and the need to be done in highly specialised centres [99]. A large meta-analysis of 17 observational studies including 2221 patients with cardiogenic shock treated with ECMO, reported that a strategy of unloading the LV was associated with $21 \%$ relative risk reduction in all-cause mortality when compared to those without unloading the LV [100]. Importantly, the predominant method to unload the LV was using IABP in $91.7 \%$ of cases [100]. Future RCT will guide the clinical management of whether and how to unload the LV in patients treated with ECMO.

\section{Role of cardiogenic shock teams}

The role of the multidisciplinary shock team is increasingly recognized as a strategy to improve outcomes in patients presenting with CS $[101,102]$. The complex pathophysiological nature of CS coupled with its sensitivity to time have prompted more centres to adopt the concept of shock teams. This includes specialists from critical care, interventional cardiology, cardiac surgery, and advanced heart failure. Early activation of the shock team is required to prompt multidisciplinary discussion regarding management, escalation and de-escalation strategies [101]. The main purpose of the shock team is to streamline the management of CS by early recognising patients with CS and targeting treatment according to the mechanism of shock. This also includes early decision regarding the use of MCS and the appropriate selection of a device. Several observational studies have reported better outcomes when a dedicated shock team is present [22,102-105]. A recent multicentral study of 1242 patients presenting with CS showed that the presence of shock team was independently associated with lower mortality (odds ratio, $0.72,95 \%$ CI 0.55 to $095, p=$
0.016) [105]. Interestingly, centres with shock teams used less MCS overall (35\% vs. 43\%) but more advanced types of MCS rather than IABP [105]. A standardized multidisciplinary protocol-based approach for the management of CS may improve outcomes. Combining this with standardised shock definitions such as the proposed classification in the recent SCAI consensus would facilitate communication among members of the shock team to guide early resuscitation and implementation of MCS according to the shock stage.

\section{Conclusions}

Management of CS remains challenging. However, the development of a shock protocol alongside better understanding of the pathophysiology of CS and optimal patient selection may help reducing mortality associated with CS. Numerous randomised clinical trials are testing the hypothesis of early initiation of MCS to confer survival benefits in a selected group of patients presenting with CS. Further assessment of patient's response after MCS implantation alongside the local expertise and the level of care at the facility play a crucial rule in the management of CS. Developing the concept of shock team, that includes interventional cardiology, cardiac surgeon, advanced heart failure and intensivist, with group discussion in a timely forum will add great value and optimal decision making for this high risk group.

\section{Author contributions}

A Al-atta and MZ - drafted the manuscript; A Abdalwahab and AGA - helped with the Figures and editing the manuscript; $\mathrm{AZ}, \mathrm{ME}$ - provided the resources and edited the manuscript; MA — conceptualized, supervise and drafted the original manuscript. All authors contributed to writing the review and edited the manuscript.

\section{Ethics approval and consent to participate}

Not applicable.

\section{Acknowledgment}

Not applicable.

\section{Funding}

This research received no external funding.

\section{Conflict of interest}

The authors declare no conflict of interest.

\section{References}

[1] van Diepen S, Katz JN, Albert NM, Henry TD, Jacobs AK, Kapur NK, et al. Contemporary Management of Cardiogenic Shock: a Scientific Statement from the American Heart Association. Circulation. 2017; 136: e232-e268.

[2] Harjola VP, Lassus J, Sionis A, Køber L, Tarvasmäki T, Spinar J, et al. Clinical picture and risk prediction of short-term mortality 
in cardiogenic shock. European Journal of Heart Failure. 2015; 17: 501-509.

[3] Ibanez B, James S, Agewall S, Antunes MJ, Bucciarelli-Ducci C, Bueno H, et al. 2017 ESC Guidelines for the management of acute myocardial infarction in patients presenting with STsegment elevation: The Task Force for the management of acute myocardial infarction in patients presenting with ST-segment elevation of the European Society of Cardiology (ESC). European Heart Journal. 2018; 39: 119-177.

[4] Combes A, Price S, Slutsky AS, Brodie D. Temporary circulatory support for cardiogenic shock. The Lancet. 2020; 396: 199212.

[5] Osman M, Syed M, Patibandla S, Sulaiman S, Kheiri B, Shah MK, et al. Fifteen-Year Trends in Incidence of Cardiogenic Shock Hospitalization and in-Hospital Mortality in the United States. Journal of the American Heart Association. 2021; 10: e021061.

[6] Thiele H, Ohman EM, de Waha-Thiele S, Zeymer U, Desch S. Management of cardiogenic shock complicating myocardial infarction: an update 2019. European Heart Journal. 2019; 40: 2671-2683.

[7] Baran DA, Grines CL, Bailey S, Burkhoff D, Hall SA, Henry $\mathrm{TD}$, et al. SCAI clinical expert consensus statement on the classification of cardiogenic shock: This document was endorsed by the American College of Cardiology (ACC), the American Heart Association (AHA), the Society of Critical Care Medicine (SCCM), and the Society of Thoracic Surgeons (STS) in April 2019. Catheterization and Cardiovascular Interventions. 2019; 94: 29-37.

[8] Killip T 3rd, Kimball JT. Treatment of myocardial infarction in a coronary care unit. A two year experience with 250 patients. The American Journal of Cardiology. 1967; 20: 457-464.

[9] Vahdatpour C, Collins D, Goldberg S. Cardiogenic Shock. Journal of the American Heart Association. 2019; 8: e011991.

[10] Thiele H, Akin I, Sandri M, Fuernau G, de Waha S, Meyer-Saraei $\mathrm{R}$, et al. PCI Strategies in Patients with Acute Myocardial Infarction and Cardiogenic Shock. The New England Journal of Medicine. 2017; 377: 2419-2432.

[11] Ponikowski P, Voors AA, Anker SD, Bueno H, Cleland JGF, Coats AJS, et al. 2016 ESC Guidelines for the diagnosis and treatment of acute and chronic heart failure: the Task Force for the diagnosis and treatment of acute and chronic heart failure of the European Society of Cardiology (ESC)Developed with the special contribution of the Heart Failure Association (HFA) of the ESC. European Heart Journal. 2016; 37: 2129-2200.

[12] Hochman JS, Sleeper LA, Webb JG, Sanborn TA, White HD, Talley JD, et al. Early revascularization in acute myocardial infarction complicated by cardiogenic shock. SHOCK Investigators. Should We Emergently Revascularize Occluded Coronaries for Cardiogenic Shock. New England Journal of Medicine. 1999; 341: 625-634.

[13] Thiele H, Zeymer U, Neumann FJ, Ferenc M, Olbrich H, Hausleiter $\mathrm{J}$, et al. Intraaortic balloon support for myocardial infarction with cardiogenic shock. The New England Journal of Medicine. 2012; 367: 1287-1296.

[14] Alexander JH, Reynolds HR, Stebbins AL, Dzavik V, Harrington RA, Van de Werf F, et al. Effect of tilarginine acetate in patients with acute myocardial infarction and cardiogenic shock: the TRIUMPH randomized controlled trial. The Journal of the American Medical Association. 2007; 297: 1657-1666.

[15] Bauer T, Zeymer U, Hochadel M, Möllmann H, Weidinger F, Zahn R, et al. Use and outcomes of multivessel percutaneous coronary intervention in patients with acute myocardial infarction complicated by cardiogenic shock (from the EHS-PCI Registry). The American Journal of Cardiology. 2012; 109: 941946.
[16] Hanson ID, Tagami T, Mando R, Kara Balla A, Dixon SR, Timmis S, et al. SCAI shock classification in acute myocardial infarction: Insights from the National Cardiogenic Shock Initiative. Catheterization and Cardiovascular Interventions. 2020; 96: 1137-1142.

[17] Hochman JS. Cardiogenic shock complicating acute myocardial infarction: expanding the paradigm. Circulation. 2003; 107: 2998-3002.

[18] Jones TL, Nakamura K, McCabe JM. Cardiogenic shock: evolving definitions and future directions in management. Open Heart. 2019; 6: e000960.

[19] Jacobs AK, Leopold JA, Bates E, Mendes LA, Sleeper LA, White $\mathrm{H}$, et al. Cardiogenic shock caused by right ventricular infarction: a report from the SHOCK registry. Journal of the American College of Cardiology. 2003; 41: 1273-1279.

[20] Kapur NK, Esposito ML, Bader Y, Morine KJ, Kiernan MS, Pham DT, et al. Mechanical Circulatory Support Devices for Acute Right Ventricular Failure. Circulation. 2017; 136: 314 326.

[21] Fincke R, Hochman JS, Lowe AM, Menon V, Slater JN, Webb $\mathrm{JG}$, et al. Cardiac power is the strongest hemodynamic correlate of mortality in cardiogenic shock: a report from the SHOCK trial registry. Journal of the American College of Cardiology. 2004; 44: 340-348.

[22] Basir MB, Kapur NK, Patel K, Salam MA, Schreiber T, Kaki A, et al. Improved Outcomes Associated with the use of Shock Protocols: Updates from the National Cardiogenic Shock Initiative. Catheterization and Cardiovascular Interventions. 2019; 93: 1173-1183.

[23] Morine KJ, Kiernan MS, Pham DT, Paruchuri V, Denofrio D, Kapur NK. Pulmonary Artery Pulsatility Index is Associated with Right Ventricular Failure after Left Ventricular Assist Device Surgery. Journal of Cardiac Failure. 2016; 22: 110-116.

[24] Korabathina R, Heffernan KS, Paruchuri V, Patel AR, Mudd JO, Prutkin JM, et al. The pulmonary artery pulsatility index identifies severe right ventricular dysfunction in acute inferior myocardial infarction. Catheterization and Cardiovascular Interventions. 2012; 80: 593-600.

[25] Garan AR, Kanwar M, Thayer KL, Whitehead E, Zweck E, Hernandez-Montfort J, et al. Complete Hemodynamic Profiling with Pulmonary Artery Catheters in Cardiogenic Shock is Associated with Lower in-Hospital Mortality. JACC: Heart Failure. 2020; 8: 903-913.

[26] Hochman JS, Sleeper LA, White HD, Dzavik V, Wong SC, Menon $\mathrm{V}$, et al. One-year survival following early revascularization for cardiogenic shock. The Journal of the American Medical Association. 2001; 285: 190-192.

[27] Lemor A, Basir MB, Patel K, Kolski B, Kaki A, Kapur NK, et al. Multivessel Versus Culprit-Vessel Percutaneous Coronary Intervention in Cardiogenic Shock. JACC: Cardiovascular Interventions. 2020; 13: 1171-1178.

[28] Omer MA, Brilakis ES, Kennedy KF, Alkhouli M, Elgendy IY, Chan PS, et al. Multivessel Versus Culprit-Vessel Percutaneous Coronary Intervention in Patients with Non-ST-Segment Elevation Myocardial Infarction and Cardiogenic Shock. JACC: Cardiovascular Interventions. 2021; 14: 1067-1078.

[29] Asfar P, Meziani F, Hamel JF, Grelon F, Megarbane B, Anguel $\mathrm{N}$, et al. High versus low blood-pressure target in patients with septic shock. The New England Journal of Medicine. 2014; 370: 1583-1593.

[30] De Backer D, Biston P, Devriendt J, Madl C, Chochrad D, Aldecoa $\mathrm{C}$, et al. Comparison of dopamine and norepinephrine in the treatment of shock. The New England Journal of Medicine. 2010; 362: 779-789.

[31] Levy B, Clere-Jehl R, Legras A, Morichau-Beauchant T, Leone $\mathrm{M}$, Frederique G, et al. Epinephrine Versus Norepinephrine for 
Cardiogenic Shock after Acute Myocardial Infarction. Journal of the American College of Cardiology. 2018; 72: 173-182.

[32] Levy B, Perez P, Perny J, Thivilier C, Gerard A. Comparison of norepinephrine-dobutamine to epinephrine for hemodynamics, lactate metabolism, and organ function variables in cardiogenic shock. a prospective, randomized pilot study. Critical Care Medicine. 2011; 39: 450-455.

[33] Landoni G, Lomivorotov VV, Alvaro G, Lobreglio R, Pisano A, Guarracino F, et al. Levosimendan for Hemodynamic Support after Cardiac Surgery. New England Journal of Medicine. 2017; 376: 2021-2031.

[34] Mathew R, Di Santo P, Jung RG, Marbach JA, Hutson J, Simard $\mathrm{T}$, et al. Milrinone as Compared with Dobutamine in the Treatment of Cardiogenic Shock. New England Journal of Medicine. 2021; 385: 516-525.

[35] Pirracchio R, Parenica J, Resche Rigon M, Chevret S, Spinar $\mathrm{J}$, Jarkovsky J, et al. The effectiveness of inodilators in reducing short term mortality among patient with severe cardiogenic shock: a propensity-based analysis. PLoS ONE. 2013; 8: e71659.

[36] Burkhoff D, Naidu SS. The science behind percutaneous hemodynamic support: a review and comparison of support strategies. Catheterization and Cardiovascular Interventions. 2012; 80: 816-829.

[37] Basir MB, Schreiber T, Dixon S, Alaswad K, Patel K, Almany S, et al. Feasibility of early mechanical circulatory support in acute myocardial infarction complicated by cardiogenic shock: The Detroit cardiogenic shock initiative. Catheterization and Cardiovascular Interventions. 2018; 91: 454-461.

[38] Kapur NK, Alkhouli MA, DeMartini TJ, Faraz H, George ZH, Goodwin MJ, et al. Unloading the Left Ventricle Before Reperfusion in Patients with Anterior ST-Segment-Elevation Myocardial Infarction. Circulation. 2019; 139: 337-346.

[39] Udesen NJ, Møller JE, Lindholm MG, Eiskjær H, Schäfer A, Werner N, et al. Rationale and design of DanGer shock: DanishGerman cardiogenic shock trial. American Heart Journal. 2019; 214: $60-68$.

[40] Thiele H, Freund A, Gimenez MR, de Waha-Thiele S, Akin I, Pöss $\mathrm{J}$, et al. Extracorporeal life support in patients with acute myocardial infarction complicated by cardiogenic shock - Design and rationale of the ECLS-SHOCK trial. American Heart Journal. 2021; 234: 1-11.

[41] Ostadal P, Rokyta R, Kruger A, Vondrakova D, Janotka M, Smíd $\mathrm{O}$, et al. Extra corporeal membrane oxygenation in the therapy of cardiogenic shock (ECMO-CS): rationale and design of the multicenter randomized trial. European Journal of Heart Failure. $2017 ; 19$.

[42] Lusebrink E, Orban M, Kupka D, Scherer C, Hagl C, Zimmer $\mathrm{S}$, et al. Prevention and treatment of pulmonary congestion in patients undergoing venoarterial extracorporeal membrane oxygenation for cardiogenic shock. European Heart Journal. 2020; 41: 3753-3761.

[43] Waksman R, Weiss AT, Gotsman MS, Hasin Y. Intra-aortic balloon counterpulsation improves survival in cardiogenic shock complicating acute myocardial infarction. European Heart Journal. 1993; 14: 71-74.

[44] Anderson RD, Ohman EM, Holmes DR Jr, Col I, Stebbins AL, Bates ER, et al. Use of intraaortic balloon counterpulsation in patients presenting with cardiogenic shock: observations from the GUSTO-I Study. Global Utilization of Streptokinase and TPA for Occluded Coronary Arteries. Journal of the American College of Cardiology. 1997; 30: 708-715.

[45] De Silva K, Lumley M, Kailey B, Alastruey J, Guilcher A, Asrress $\mathrm{KN}$, et al. Coronary and microvascular physiology during intra-aortic balloon counterpulsation. JACC: Cardiovascular Interventions. 2014; 7: 631-640.
[46] Prondzinsky R, Unverzagt S, Russ M, Lemm H, Swyter M, Wegener $\mathrm{N}$, et al. Hemodynamic effects of intra-aortic balloon counterpulsation in patients with acute myocardial infarction complicated by cardiogenic shock: the prospective, randomized IABP shock trial. Shock. 2012; 37: 378-384.

[47] Thiele H, Zeymer U, Thelemann N, Neumann FJ, Hausleiter J, Abdel-Wahab M, et al. Intraaortic Balloon Pump in Cardiogenic Shock Complicating Acute Myocardial Infarction: Long-Term 6-Year Outcome of the Randomized IABP-SHOCK II Trial. Circulation. 2018. (in press)

[48] Ahmad Y, Sen S, Shun-Shin MJ, Ouyang J, Finegold JA, AlLamee RK, et al. Intra-aortic Balloon Pump Therapy for Acute Myocardial Infarction. JAMA Internal Medicine. 2015; 175: 931-939.

[49] Perera D, Stables R, Thomas M, Booth J, Pitt M, Blackman D, et al. Elective intra-aortic balloon counterpulsation during highrisk percutaneous coronary intervention: a randomized controlled trial. The Journal of the American Medical Association. 2010; 304: 867-874.

[50] Perera D, Stables R, Clayton T, De Silva K, Lumley M, Clack L, et al. Long-term mortality data from the balloon pump-assisted coronary intervention study (BCIS-1): a randomized, controlled trial of elective balloon counterpulsation during high-risk percutaneous coronary intervention. Circulation. 2013; 127: 207-212.

[51] Gu J, Hu W, Xiao H, Feng X, Song Z, Chen Y, et al. Prophylactic intra-aortic balloon pump reduces C-reactive protein levels and early mortality in high-risk patients undergoing percutaneous coronary intervention. Acta Cardiologica. 2011; 66: 499504.

[52] Patel MR, Smalling RW, Thiele H, Barnhart HX, Zhou Y, Chandra $\mathrm{P}$, et al. Intra-aortic balloon counterpulsation and infarct size in patients with acute anterior myocardial infarction without shock: the CRISP AMI randomized trial. The Journal of the American Medical Association. 2011; 306: 1329-1337.

[53] Sjauw KD, Engström AE, Vis MM, van der Schaaf RJ, Baan J Jr, Koch KT, et al. A systematic review and meta-analysis of intraaortic balloon pump therapy in ST-elevation myocardial infarction: should we change the guidelines? European Heart Journal. 2009; 30: 459-468.

[54] Gonzalez LS, Chaney MA. Intraaortic Balloon Pump Counterpulsation, Part I: History, Technical Aspects, Physiologic Effects, Contraindications, Medical Applications/Outcomes. Anesthesia and Analgesia. 2020; 131: 776-791.

[55] Erdogan HB, Goksedef D, Erentug V, Polat A, Bozbuga N, Mansuroglu D, et al. In which patients should sheathless IABP be used? An analysis of vascular complications in 1211 cases. Journal of Cardiac Surgery. 2006; 21: 342-346.

[56] Remmelink M, Sjauw KD, Henriques JP, de Winter RJ, Koch $\mathrm{KT}$, van der Schaaf RJ, et al. Effects of left ventricular unloading by Impella recover LP2.5 on coronary hemodynamics. Catheterization and Cardiovascular Interventions. 2007; 70: 532-537.

[57] Meyns B, Dens J, Sergeant P, Herijgers P, Daenen W, Flameng W. Initial experiences with the Impella device in patients with cardiogenic shock - Impella support for cardiogenic shock. The Thoracic and Cardiovascular Surgeon. 2003; 51: 312-317.

[58] Lauten A, Engstrom AE, Jung C, Empen K, Erne P, Cook S, et al. Percutaneous left-ventricular support with the Impella-2.5assist device in acute cardiogenic shock: results of the ImpellaEUROSHOCK-registry. Circulation. Heart Failure. 2013; 6: 23-30.

[59] Seyfarth M, Sibbing D, Bauer I, Fröhlich G, Bott-Flügel L, Byrne R, et al. A randomized clinical trial to evaluate the safety and efficacy of a percutaneous left ventricular assist device versus intra-aortic balloon pumping for treatment of cardiogenic shock caused by myocardial infarction. Journal of the American College of Cardiology. 2008; 52: 1584-1588. 
[60] Ouweneel DM, Eriksen E, Sjauw KD, van Dongen IM, Hirsch A, Packer EJS, et al. Percutaneous Mechanical Circulatory Support Versus Intra-Aortic Balloon Pump in Cardiogenic Shock after Acute Myocardial Infarction. Journal of the American College of Cardiology. 2017; 69: 278-287.

[61] Engström AE, Cocchieri R, Driessen AH, Sjauw KD, Vis MM, Baan J, et al. The Impella 2.5 and 5.0 devices for ST-elevation myocardial infarction patients presenting with severe and profound cardiogenic shock: The Academic Medical Center intensive care unit experience. Critical Care Medicine. 2011; 39: 2072-2079.

[62] Boshara A, Patel A, Alasaad M, Dutcheshen KJ, LaLonde TA, Schreiber TL, et al. Cardiogenic Shock Complicating Acute Myocardial Infarction Treated with Percutaneous Coronary Intervention Supported by Impella: Implications of Advanced Age and Refractory Shock on Outcomes. Critical Care Explorations. 2021; 3: e0447.

[63] Wernly B, Seelmaier C, Leistner D, Stähli BE, Pretsch I, Lichtenauer $\mathrm{M}$, et al. Mechanical circulatory support with Impella versus intra-aortic balloon pump or medical treatment in cardiogenic shock - a critical appraisal of current data. Clinical Research in Cardiology. 2019; 108: 1249-1257.

[64] Schrage B, Ibrahim K, Loehn T, Werner N, Sinning JM, Pappalardo F, et al. Impella Support for Acute Myocardial Infarction Complicated by Cardiogenic Shock. Circulation. 2019; 139: $1249-1258$

[65] O'Neill WW, Schreiber T, Wohns DH, Rihal C, Naidu SS, Civitello AB, et al. The current use of Impella 2.5 in acute myocardial infarction complicated by cardiogenic shock: results from the USpella Registry. Journal of Interventional Cardiology. 2014; 27: 1-11.

[66] Basir MB, Schreiber TL, Grines CL, Dixon SR, Moses JW, Maini BS, et al. Effect of Early Initiation of Mechanical Circulatory Support on Survival in Cardiogenic Shock. The American Journal of Cardiology. 2017; 119: 845-851.

[67] Vargas KG, Jager B, Kaufmann CC, Biagioli A, Watremez S, Gatto F, et al. Impella in cardiogenic shock following acute myocardial infarction: a systematic review and meta-analysis. Wiener Klinische Wochenschrift. 2020; 132: 716-725.

[68] Sjauw KD, Konorza T, Erbel R, Danna PL, Viecca M, Minden $\mathrm{H}$, et al. Supported high-risk percutaneous coronary intervention with the Impella 2.5 device the Europella registry. Journal of the American College of Cardiology. 2009; 54: 2430-2434.

[69] Dixon SR, Henriques JP, Mauri L, Sjauw K, Civitello A, Kar $\mathrm{B}$, et al. A prospective feasibility trial investigating the use of the Impella 2.5 system in patients undergoing high-risk percutaneous coronary intervention (The PROTECT I Trial): initial U.S. experience. JACC: Cardiovascular Interventions. 2009; 2: 91-96.

[70] Henriques JP, Remmelink M, Baan J Jr, van der Schaaf RJ, Vis MM, Koch KT, et al. Safety and feasibility of elective high-risk percutaneous coronary intervention procedures with left ventricular support of the Impella Recover LP 2.5. The American Journal of Cardiology. 2006; 97: 990-992.

[71] O'Neill WW, Kleiman NS, Moses J, Henriques JPS, Dixon S, Massaro J, et al. A prospective, randomized clinical trial of hemodynamic support with Impella 2.5 versus intra-aortic balloon pump in patients undergoing high-risk percutaneous coronary intervention: the PROTECT II study. Circulation. 2012; 126: $1717-1727$.

[72] Spiro J, Venugopal V, Raja Y, Ludman PF, Townend JN, Doshi SN. Feasibility and efficacy of the $2.5 \mathrm{~L}$ and $3.8 \mathrm{~L}$ impella percutaneous left ventricular support device during high-risk, percutaneous coronary intervention in patients with severe aortic stenosis. Catheterization and Cardiovascular Interventions. 2015; 85: 981-989.
[73] Singh V, Mendirichaga R, Inglessis-Azuaje I, Palacios IF, O'Neill WW. The Role of Impella for Hemodynamic Support in Patients with Aortic Stenosis. Current Treatment Options in Cardiovascular Medicine. 2018; 20: 44.

[74] Wong ASK, Sin SWC. Short-term mechanical circulatory support (intra-aortic balloon pump, Impella, extracorporeal membrane oxygenation, TandemHeart): a review. Annals of Translational Medicine. 2020; 8: 829.

[75] Kuchibhotla S, Esposito ML, Breton C, Pedicini R, Mullin A, O'Kelly R, et al. Acute Biventricular Mechanical Circulatory Support for Cardiogenic Shock. Journal of the American Heart Association. 2017; 6: e006670.

[76] Badiye AP, Hernandez GA, Novoa I, Chaparro SV. Incidence of Hemolysis in Patients with Cardiogenic Shock Treated with Impella Percutaneous Left Ventricular Assist Device. ASAIO Journal. 2016; 62: 11-14.

[77] Balthazar T, Vandenbriele C, Verbrugge FH, Den Uil C, Engström A, Janssens S, et al. Managing Patients with Short-Term Mechanical Circulatory Support: JACC Review Topic of the Week. Journal of the American College of Cardiology. 2021; 77: 1243-1256.

[78] Nichol G, Karmy-Jones R, Salerno C, Cantore L, Becker L. Systematic review of percutaneous cardiopulmonary bypass for cardiac arrest or cardiogenic shock states. Resuscitation. 2006; 70: 381-394.

[79] Sakamoto S, Taniguchi N, Nakajima S, Takahashi A. Extracorporeal life support for cardiogenic shock or cardiac arrest due to acute coronary syndrome. The Annals of Thoracic Surgery. 2012; 94: 1-7.

[80] Sheu JJ, Tsai TH, Lee FY, Fang HY, Sun CK, Leu S, et al. Early extracorporeal membrane oxygenator-assisted primary percutaneous coronary intervention improved 30-day clinical outcomes in patients with ST-segment elevation myocardial infarction complicated with profound cardiogenic shock. Critical Care Medicine. 2010; 38: 1810-1817.

[81] Ouweneel DM, Schotborgh JV, Limpens J, Sjauw KD, Engström AE, Lagrand WK, et al. Extracorporeal life support during cardiac arrest and cardiogenic shock: a systematic review and meta-analysis. Intensive Care Medicine. 2016; 42: 1922 1934.

[82] Smith M, Vukomanovic A, Brodie D, Thiagarajan R, Rycus P, Buscher H. Duration of veno-arterial extracorporeal life support (VA ECMO) and outcome: an analysis of the Extracorporeal Life Support Organization (ELSO) registry. Critical Care. 2017; 21: 45 .

[83] de Waha S, Fuernau G, Desch S, Eitel I, Wiedau A, Lurz P, et $a l$. Long-term prognosis after extracorporeal life support in refractory cardiogenic shock: results from a real-world cohort. EuroIntervention. 2016; 11: 1363-1371.

[84] de Waha S, Graf T, Desch S, Fuernau G, Eitel I, Pöss J, et al. Outcome of elderly undergoing extracorporeal life support in refractory cardiogenic shock. Clinical Research in Cardiology. 2017; 106: $379-385$.

[85] Lorusso R, Gelsomino S, Parise O, Mendiratta P, Prodhan P, Rycus $\mathrm{P}$, et al. Venoarterial Extracorporeal Membrane Oxygenation for Refractory Cardiogenic Shock in Elderly Patients: Trends in Application and Outcome from the Extracorporeal Life Support Organization (ELSO) Registry. The Annals of Thoracic Surgery. 2017; 104: 62-69.

[86] Brunner S, Guenther SPW, Lackermair K, Peterss S, Orban M, Boulesteix A, et al. Extracorporeal Life Support in Cardiogenic Shock Complicating Acute Myocardial Infarction. Journal of the American College of Cardiology. 2019; 73: 2355-2357.

[87] Lackermair K, Brunner S, Orban M, Peterss S, Orban M, Theiss $\mathrm{HD}$, et al. Outcome of patients treated with extracorporeal life support in cardiogenic shock complicating acute myocardial in- 
farction: 1-year result from the ECLS-Shock study. Clinical Research in Cardiology. 2021; 110: 1412-1420.

[88] Zangrillo A, Landoni G, Biondi-Zoccai G, Greco M, Greco T, Frati G, et al. A meta-analysis of complications and mortality of extracorporeal membrane oxygenation. Critical Care and Resuscitation. 2013; 15: 172-178.

[89] Lo Coco V, Lorusso R, Raffa GM, Malvindi PG, Pilato M, Martucci $\mathrm{G}$, et al. Clinical complications during veno-arterial extracorporeal membrane oxigenation in post-cardiotomy and non post-cardiotomy shock: still the achille's heel. Journal of Thoracic Disease. 2018; 10: 6993-7004.

[90] Thiele H, Sick P, Boudriot E, Diederich K, Hambrecht R, Niebauer J, et al. Randomized comparison of intra-aortic balloon support with a percutaneous left ventricular assist device in patients with revascularized acute myocardial infarction complicated by cardiogenic shock. European Heart Journal. 2005; 26: 1276-1283.

[91] Burkhoff D, Cohen H, Brunckhorst C, O'Neill WW. A randomized multicenter clinical study to evaluate the safety and efficacy of the TandemHeart percutaneous ventricular assist device versus conventional therapy with intraaortic balloon pumping for treatment of cardiogenic shock. American Heart Journal. 2006; 152: 469.e1-469.e4698.

[92] Sauren LD, Accord RE, Hamzeh K, de Jong M, van der Nagel $\mathrm{T}$, van der Veen FH, et al. Combined Impella and Intra-aortic Balloon Pump Support to Improve both Ventricular Unloading and Coronary Blood Flow for Myocardial Recovery: an Experimental Study. Artificial Organs. 2007; 31: 839-842.

[93] Bochaton T, Huot L, Elbaz M, Delmas C, Aissaoui N, Farhat F, et al. Mechanical circulatory support with the Impella(R) LP5.0 pump and an intra-aortic balloon pump for cardiogenic shock in acute myocardial infarction: The IMPELLA-STIC randomized study. Archives of Cardiovascular Diseases. 2020; 113: $237-$ 243.

[94] Li Y, Yan S, Gao S, Liu M, Lou S, Liu G, et al. Effect of an intraaortic balloon pump with venoarterial extracorporeal membrane oxygenation on mortality of patients with cardiogenic shock: a systematic review and meta-analysisdagger. European Journal of Cardio-thoracic Surgery. 2019; 55: 395-404.

[95] Vallabhajosyula S, O'Horo JC, Antharam P, Ananthaneni S, Vallabhajosyula S, Stulak JM, et al. Concomitant Intra-Aortic Balloon Pump Use in Cardiogenic Shock Requiring Veno-Arterial Extracorporeal Membrane Oxygenation. Circulation: Cardio- vascular Interventions. 2018; 11: e006930.

[96] van den Brink FS, Zivelonghi C, Vossenberg TN, Bleeker GB, Winia VL, Sjauw KD, et al. VA-ECMO with IABP is Associated With Better Outcome Than VA-ECMO Alone in the Treatment of Cardiogenic Shock in ST-Elevation Myocardial Infarction. The Journal of invasive cardiology. 2021; 33: E387-E392.

[97] Lim HS. The Physiologic Basis and Clinical Outcomes of Combined Impella and Veno-Arterial Extracorporeal Membrane Oxygenation Support in Cardiogenic Shock. Cardiology and Therapy. 2020; 9: 245-255.

[98] Patel SM, Lipinski J, Al-Kindi SG, Patel T, Saric P, Li J, et al. Simultaneous Venoarterial Extracorporeal Membrane Oxygenation and Percutaneous Left Ventricular Decompression Therapy with Impella is Associated with Improved Outcomes in Refractory Cardiogenic Shock. ASAIO Journal. 2019; 65: 21-28.

[99] Donker DW, Brodie D, Henriques JPS, Broome M. Left ventricular unloading during veno-arterial ECMO: a review of percutaneous and surgical unloading interventions. Perfusion. 2019; 34: $98-105$.

[100] Russo JJ, Aleksova N, Pitcher I, Couture E, Parlow S, Faraz M, et al. Left Ventricular Unloading during Extracorporeal Membrane Oxygenation in Patients with Cardiogenic Shock. Journal of the American College of Cardiology. 2019; 73: 654-662.

[101] Moghaddam N, Diepen S, So D, Lawler PR, Fordyce CB. Cardiogenic shock teams and centres: a contemporary review of multidisciplinary care for cardiogenic shock. ESC Heart Failure. 2021; 8: 988-998.

[102] Tehrani BN, Truesdell AG, Sherwood MW, Desai S, Tran HA Epps KC, et al. Standardized Team-Based Care for Cardiogenic Shock. Journal of the American College of Cardiology. 2019; 73: $1659-1669$.

[103] Lee F, Hutson JH, Boodhwani M, McDonald B, So D, De Roock S, et al. Multidisciplinary Code Shock Team in Cardiogenic Shock: A Canadian Centre Experience. CJC Open. 2020; 2: 249-257.

[104] Taleb I, Koliopoulou AG, Tandar A, McKellar SH, Tonna JE, Nativi-Nicolau J, et al. Shock Team Approach in Refractory Cardiogenic Shock Requiring Short-Term Mechanical Circulatory Support: A Proof of Concept. Circulation. 2019; 140: 98-100.

[105] Papolos AI, Kenigsberg BB, Berg DD, Alviar CL, Bohula E, Burke JA, et al. Management and Outcomes of Cardiogenic Shock in Cardiac ICUs with Versus without Shock Teams. Journal of the American College of Cardiology. 2021; 78: 13091317. 